\title{
DESIGN STRATEGIES FOR THE DEVELOPMENT OF LIFE-SAVING FURNITURE SYSTEMS IN THE EVENT OF AN EARTHQUAKE
}

\author{
DANIELE GALLOPPO, JACOPO MASCITTI \& LUCIA PIETRONI \\ School of Architecture and Design, University of Camerino, Italy
}

\begin{abstract}
During an earthquake, non-structural elements, such as mobile systems, furniture and equipment that set up environments, can either become obstacles and barriers that aggravate dangerous conditions especially for the elderly, children and those who have ambulation impairment or, on the contrary, they may represent a chance of survival in the event of collapses. This paper aims to investigate the possibilities to innovate and transform, from a structural and functional perspective, the design of furniture and mobile equipment, in intelligent safety systems that can contribute to the protection of life. In particular, the state of the art of earthquake-proof projects and products, are analyzed in a critical way both to highlight the "life-saving" implemented strategies and to bring out, at the same time, any latent needs that are not yet met but that can be developed in a future scenario. The aim of this analysis is the definition of a set of technical performance requirements, for the development of new "collaborative" life-saving concepts in the case of earthquakes. For the critical analysis of the state of the art, we carried out a series of data collection activities of patents and anti-seismic furniture products and an interdisciplinary research, concerning the health conditions and the conditions of psychophysical stress that people undergo during a seismic event. The data collection was conducted through the analysis of the most recent scientific publications and technical sheets of existing products, and also through interviews with specific figures who were directly involved in the last seismic events that hit the centre of Italy. The paper shows the results of this research which, in turn, demonstrates how the theme of furniture design and non-structural elements for the preservation of life in the event of earthquake is current and promising; it also identifies design strategies for the development of systems of life-saving furniture, in a systemic and collaborative perspective.
\end{abstract}

Keywords: design for safety, earthquake proof furniture, furniture design.

\section{INTRODUCTION}

The seismic events of central Italy, especially those of 2016 that affected the municipalities of Amatrice and those surrounding the city of Ascoli Piceno, have rekindled the debate on the safety of public and private buildings in our country, especially for those that are located in historical centres. The last disastrous seismic events have highlighted, for the umpteenth time, the precariousness and inadequacy not only of the structures that constitute the heart of our cities and countries but, in particular, of sensitive buildings for communities such as schools and administrative centres. At the same time, recent telluric events have shown again the substantial inadequacy of the usual domestic practices for survival in the event of an earthquake, such as sheltering under the door lintels, whose purpose is to give greater chances of survival in case of failures and collapses, as now widely described by the theories of the "triangle of life" and by those of the "drop, cover and hold on" [1]. During an earthquake, it is not only the architectural structures that can cause serious damage to people: even the furniture systems, the objects and the equipment that set up the space can become the cause of death or obstacles and barriers which aggravate the dangerous conditions, in particular for some sensitive categories of people such as elderly, children and the disabled. On the contrary, in rare cases, the furniture can be a temporary shelter, thanks to their ability to withstand the weight of collapsing structures. We can consider these occasional shelters as 
passive protection systems, as well as some devices designed for safety in other areas (airbag systems, accident prevention clothing, etc.). Their different behaviour depends on how they were conceived, designed and implemented. For many years now, there are available on the market various devices for fixing non-structural elements - such as wardrobes, electronic equipment, shelves and other potentially dangerous furniture - to the buildings' structure, so as to allow them to be secured to the walls. These are simple systems such as safety belts, metal brackets, door locking systems and anti-tipping gel pads. In 2005, a first non-structural elements study was conducted in order to provide guidelines for risk reduction and for securing the above mentioned elements through the use of these devices [2]. However these systems are effective only if placed inside buildings made with anti-seismic criteria, as the Japanese experience shows; instead they are totally inadequate, when used in a context of historic architecture such as the Italian one, which is characterised by a widespread uncertainty of the behaviour of the structures in the event of an earthquake. To date, intervention solutions have also been developed that offer greater life-saving performance, but that are also characterised by more invasive installation methods. These are hermetic structures such as bunkers and lifesaving capsules that are installed in homes and sometimes offices and public places. An interesting case is the K 107 capsule, a life-saving cell in case of natural disasters which has been developed in Mexico in 2018, in collaboration with the aerospace industry which is now in the commercialization phase.

Certainly the issue of security in the event of an earthquake, does not only concern the safeguarding of people, but also the one of cultural heritage, especially museum's works of art. In 2001, for example, the ENEA (Italian National Agency for New Technologies, Energy and Sustainable Economic Development) conducted research for the development of criteria and methods for operating interventions that are respectful of cultural values and at the same time rational and efficient, able to guarantee the reduction of foreseeable damages in the event of an earthquake. One of the strategies identified by the study and then adopted was that of integrating insulating bases to the showcases in charge of safeguarding the works of art. One of the main results of this research is a software, followed by a manual [3] addressed to the employees, with the guidelines to be followed for the protection of works of art in the event of an earthquake. A similar study but aimed at the development of life-saving furniture dates back to 2015, when four researchers from the "Forestry College of the Sichuan Agricultural University" [4] proposed a first reflection on the generation of life-saving furniture in the event of natural disasters, also spelling out some possible general design principles. To date, the state of the art and the reference literature, still appear little investigated and developed, especially under a point of view of seismic adaptation and safety of those contexts considered to be the most sensitive, such as the historical centre of areas with high seismic hazard.

Being aware that today, the processes of adaptation and securing of historic buildings in Italy, will be slow and expensive, it is necessary to envisage alternative roads to give greater safety to the communities that live in areas with high seismic risk.

One of these is the use of furniture capable of not representing an aggravation of danger but, on the contrary, act as a shelter in the event of an earthquake. Schools and public buildings represent the most critical contexts in Italy, in which the issue of passive safety provided by furniture elements can find a greater development.

\section{THE REFERENCE CONTEXT}

Historically, seismic engineering has focused primarily on the structural response of buildings subject to the earthquake, and on how to mitigate the damage caused to buildings. However in the last ten years, the design vision of the concept of safety within an architectural 
structure has greatly expanded since it has been recognized - even for non-structural elements - a strategic anti-seismic role, given that they can collaborate for the safety of the building itself and for the protection of people.

In many seismic events, it has been observed that, inadequately designed non-structural elements, can become a danger to human safety: an emblematic example is the 1995 Kobe earthquake, in which 33 people died crushed by the overturning of some types of home furnishings. However the furniture can also represent a precious opportunity for salvation, as observed in the 2017 Ischia earthquake, in which a newborn child has found vital shelter in the overturning of the cradle, which has protected him from being crushed by the rubble.

In the last years, the interest on the issue of seismic adaptation of non-structural elements has progressively grown, particularly after the Kobe earthquake. In 2008, Kimiro Meguro of the University of Tokyo conducted a first study on the behaviour of the environments for the anti-overturning system [5].

The ever increasing attention to the theme is also demonstrated by the analysis of the increase in patent applications, and by the patents granted since 1995 at an international level, relating to new furniture solutions, for safety and protection in the event of an earthquake in the domestic environment. Patent development of life-saving furniture in the event of an earthquake from 1995 until today. The following diagram (Fig. 1) shows the main CPC classifications (Cooperative Patent Classification): A47C - furniture for sitting or lying down

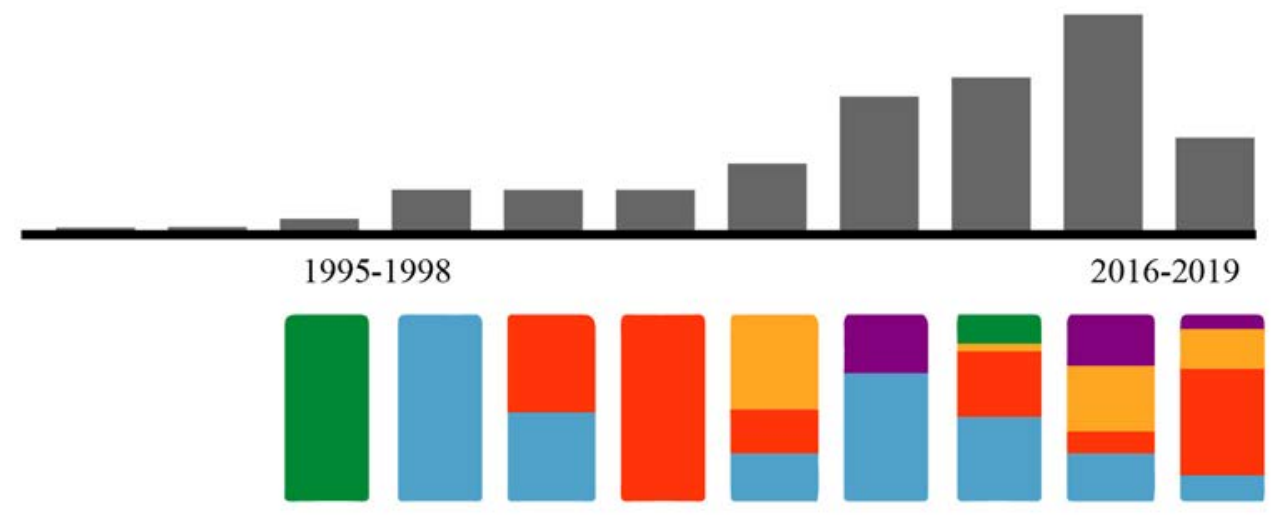

CPCs

Figure 1: The main CPC (cooperative patent classifications). 
and furniture that can be transformed into other types of furniture; E04H - structures for buildings to carry out special purposes (in particular E04H9/002 - earthquake-resistant structures and protection cells placed inside buildings); A62B - life-saving devices (in particular A62B31/00 - mobile shelters including respiratory protection devices); G08B signalling and alarm systems; A47B - tables, desks, cabinets and office furniture.

To further confirm the interest on the subject of furnishing design capable of providing protection from the earthquake, in addition to the aforementioned patent phenomenon, there is a growing proposal and dissemination of competitions of ideas and projects, aimed at engineers, architects and designers worldwide. The 2016 international competition "Creation de mobilier parasismiquedesign of furniture earthquake-resistant" [6] announced by the Order of French Architects - following the Amatrice earthquake of the same year - had as objective the development of design responses for the domestic environment, able to provide shelter in the event of an earthquake. In 2017, the magazine "Eleven Magazine" for the seventh edition of its annual competition, launched the theme "Shelter 48 Emergency LifeSupport Design", inviting its audience to face the subject of protecting the victims during the very first 48 hours following a natural disaster. Recently, the Italian National Association of Earthquake Engineering (ANIDIS) for its XVIII National Conference - which will be held next September in Ascoli Piceno - has included, among its discussion sessions, a session specifically dedicated to non-structural elements entitled "Industrial research on seismic performance of non-structural elements" [7]. In conclusion, until very recently, the market of products and devices for safety and protection from earthquakes - mainly of Japanese manufacture - concerned only systems of adaptation and easy installation, in order to secure traditional furniture on the walls, and reduce the possibility of overturning (i.e. metal brackets, straps, anti-vibration supports, etc.) [8]. Driven by the growing social demand for safety in the event of an earthquake, some companies in the furnishing sector, have begun to invest privately in research and development activities to implement anti-seismic functions within their products. This is the case of the movable walls of the Mangini Company [9] and of the life-saving furniture proposals of the American company LifeGuard Structures [10].

\section{OBJECTIVE OF THE RESEARCH}

The purpose of this research is to critically analyze the offer of lifesaving furniture solutions in the event of an earthquake, in the form of commercial products, patents, prototypes and concepts for both public and private contexts, in order to bring out the aspects of the design deemed to be of greatest interest and, in addition, to highlight any critical issues. Therefore the final objective of this paper is to bring out a series of new technical-performance requirements in a life-saving key for furniture products, aimed at the school and office sectors in the event of an earthquake. The contribution of this research to the state of the art of the technical scientific literature of reference, is represented by the methodology of analysis and critical comparison of the already developed furniture that is adopted and by the design indications that derive from it, useful to designers and furniture companies interested in the development of earthquake-proof furniture for the school and office sectors.

\section{METHODOLOGY AND PHASES OF RESEARCH}

The research conducted wanted to critically analyze the state of the art of life-saving furnishing projects in the event of an earthquake, for already developed public and private contexts, whether they are commercialized products, patents, prototypes or concepts, in order to bring out the design aspects considered most relevant to implement the life-saving performance in the event of an earthquake and to highlight, moreover, any latent needs not yet emerged or resolved, in relation to the same topic. The analysis of the individual furniture 
was subsequently summarized through the creation and use of a reasoned form, necessary to explain both the life-saving design strategies identified and the anti-seismic performances obtained. The methodology used to conduct this survey is divided into four macro phases:

1. Preliminary research on the technical-scientific literature currently available;

2. Development of a summary analysis sheet;

3. Indexing of the processed forms, in relation to the identified lifesaving strategies;

4. Summary of the results and definition of a set of technical performance requirements for the development of life-saving furniture in the event of an earthquake.

\subsection{Preliminary research}

In the first phase of preliminary research, a series of on-desk and infield activities have been started, in order to find the largest number of data and information on the technical-scientific literature that has already dealt with the topic that is the object of this paper, i.e. the analysis of furniture and life-saving devices in the event of an earthquake. For the search of previous patents, some specialized search engines have been consulted such as: Google Patent, Espacenet and UIBM, using the following keywords: "lifesaving furniture", "seismic furniture", "shelter seismic desk/table", "Seismic furniture seismic". The same keywords, translated into Italian, were used on the Italian patent site. The commercial products were investigated by collecting the technical data sheets provided by the companies and the multimedia material available online.

The identification, collection and indexing of case studies, lasted three months and were carried out with an interdisciplinary approach, involving researchers from the University of Camerino - coming from the two subject areas of "Industrial Design" and "Structural Engineering" - and an administrative employee, expert in "protection of intellectual property and patents".

\subsection{Development of a summary sheet}

The product sheet has been developed (Fig. 2) in such a way as to simplify the operations of archiving and reading important data, i.e. those deemed to be the most consistent with the objectives of the research. The cataloguing phase saw the development of a summary sheet that provides a general overview of the product, followed by a detailed sheet that contains further information. Each sheet has a colour code that identifies the design deepening state of the product under examination: light blue for the concepts, red for prototypes, green for patents and orange for marketed products. The layout of the summary sheet is composed of four parts: the type of furniture analyzed and the commercial name are specified in the coloured bar at the top; further down on the left are the details of the company or designer (or inventor) together with the country of origin, the year of production or design in the case of concepts or the year of deposit in the case of a patent; on the right, in addition to a brief description, there are logos that identify the dimensional characteristics and the technical and life-saving performances of the analyzed product; in the central part are the images of the product and finally, at the bottom on the right there is a link to an explanatory video of the product (when provided by the companies). The detail sheet shows additional information regarding technical details and insights on technological aspects. The drawings and features of the product are described in the left column, while the reference images are shown on the right. Below the layout of product sheet with the main information and technical details is showed. 

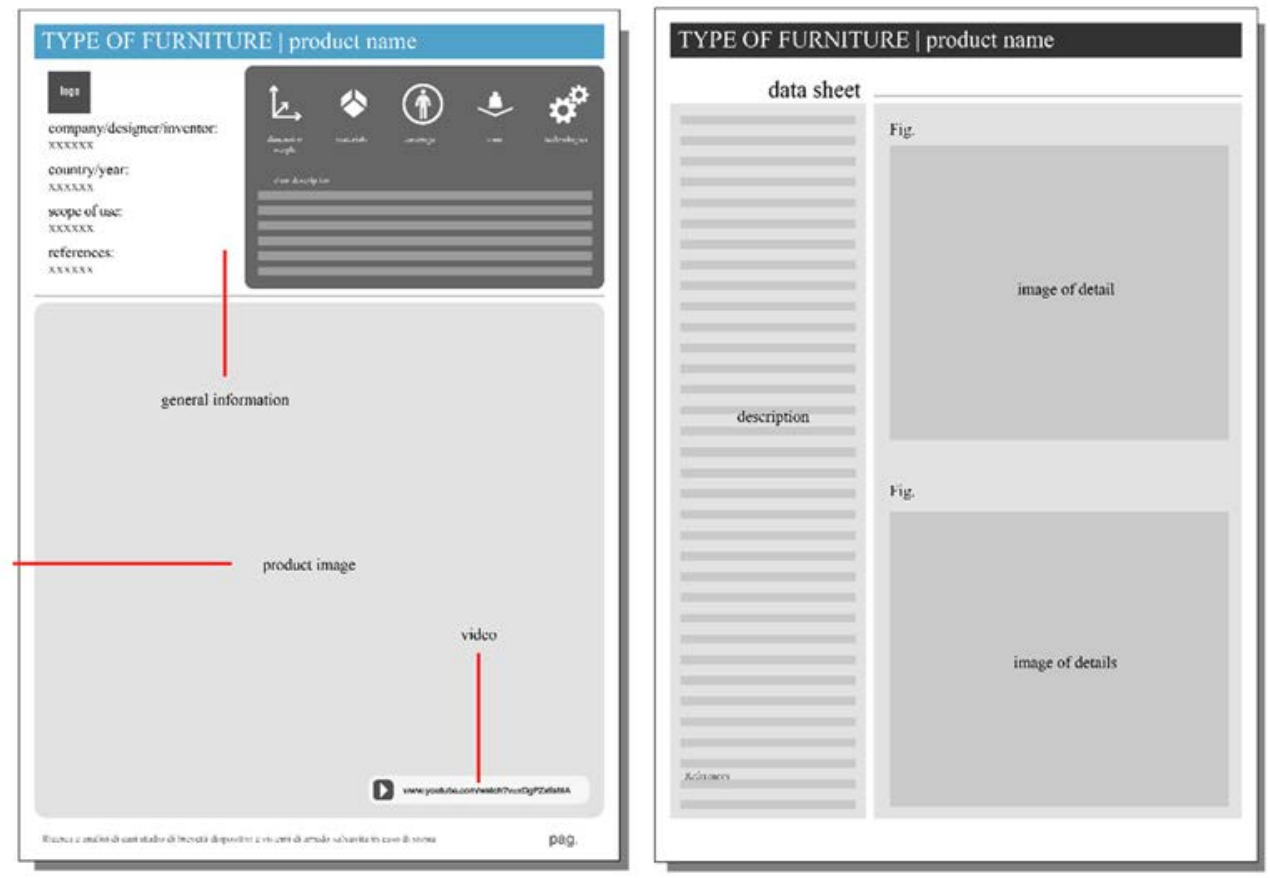

Figure 2: Data sheet developed.

4.3 Indexing of the sheets in relation to the identified life-saving strategies

In the third phase, the 42 sheets developed were divided into four macro groups: furniture with high mechanical resistance, survival cells and capsules, transformable furniture and collaborating systems. By furniture with high mechanical resistance (Fig. 3) we mean some types of consolidated furniture such as tables, desks, counters, etc. characterized by improved mechanical resistance to static and dynamic loads; the safety procedure consists of: seeking shelter under the furniture and waiting for help, according to the practice of survival of the "drop, cover, hold-on". Within this category, 14 products were listed.
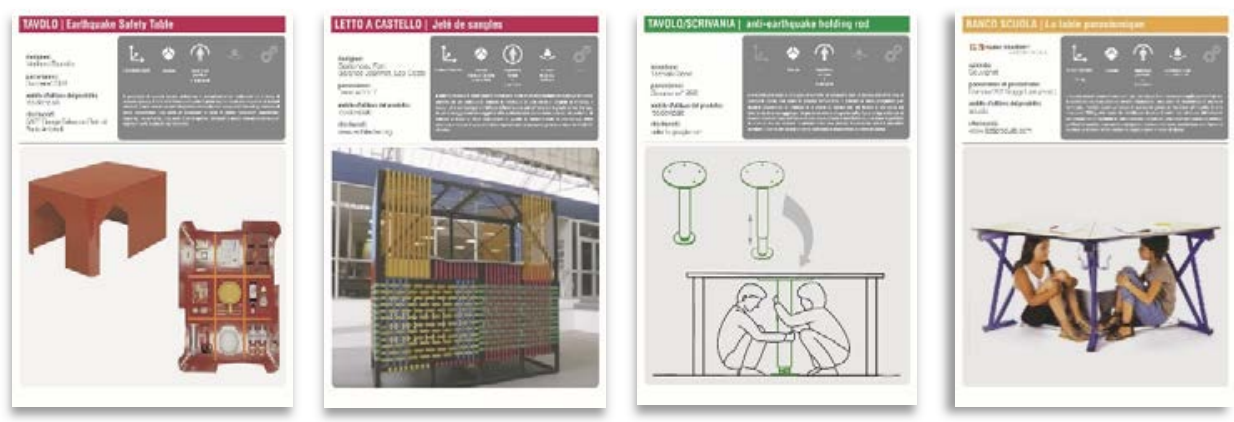

Figure 3: Four examples of furniture with high mechanical resistance. 
By survival cells and capsules (Fig. 4), reference is made to all those anti seismic design solutions in which people, in order to be safe, need to reach a sort of small shelter or bunker completely closed, which, in addition to sheltering against structural collapses, it is also able to isolate the occupant from external harmful agents due to intense seismic activity: dust, gas leaks, etc. In this category, 11 products were listed.
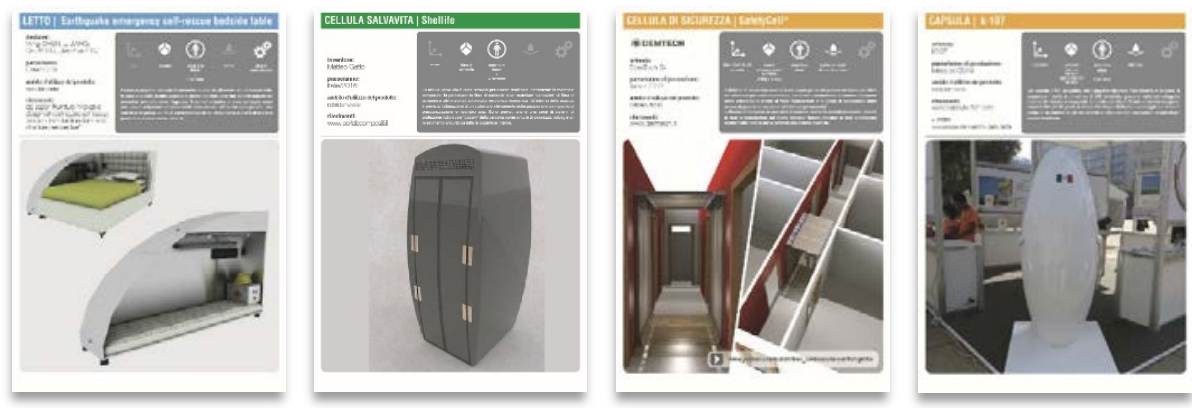

Figure 4: Four examples of survival cells and capsules.

By transformable furniture (Fig. 5) we mean those types of furniture equipped with a series of accessories that can either be activated manually or equipped with electronic sensors, which are able to trigger mechatronic systems, in turn capable of transforming the object into a bunker or into a system, that is resilient to the earthquake stresses and loads. 13 products were listed in this category.
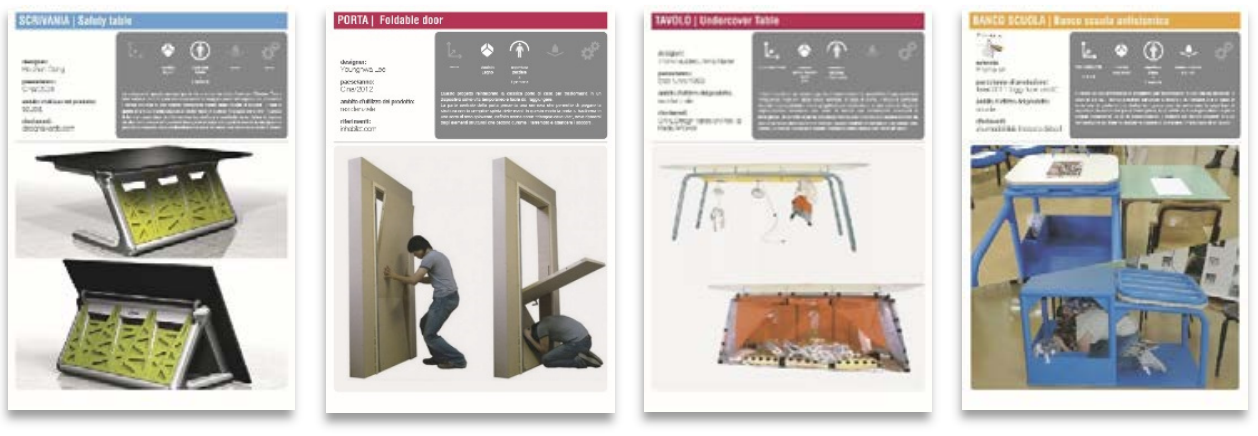

Figure 5: Four examples of transformable furniture.

By collaborative systems (Fig. 6) we mean those design solutions that work together with the building structure to secure people; in particular, by the term "collaborating", we mean the ability of a product to contribute positively to the maintenance of the static configuration of a building body, for example through a tenacious system of stiffening to be installed in a room, or a system able to follow the movements and oscillations of a building during an earthquake, thus drastically reducing the possibilities of generating barriers and obstacles. Within this category, 4 products were filed. 

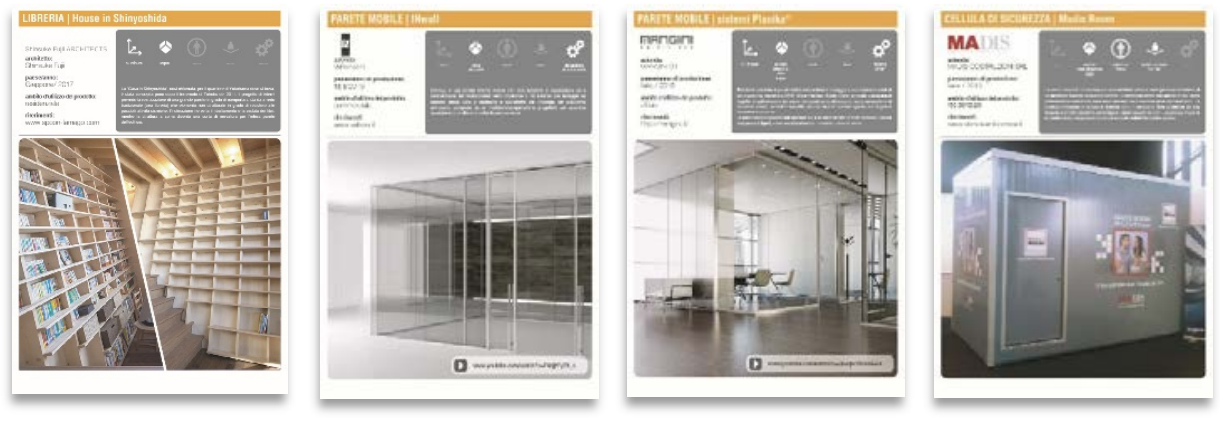

Figure 6: Four examples of collaborating systems.

\subsection{Development summary sheet of the life-saving strategies adopted}

Through the analysis and the study of the product data sheets, it was possible to frame at least three levels of project intervention within the various seismic hazard scenarios (historical buildings and modern buildings), which we will define for simplicity: "light", "intermediate" and "heavy". The first two concern the single piece of furniture while the third concerns the safety of a certain space of the building. More precisely, with the term "light", reference is made to the use of anti-tipping and safety devices for some furniture and electronic equipment, for example: metal brackets, belts, anti-tipping gel pads, systems locking of the doors, etc. The term "intermediate" is used to indicate the installation of furniture and devices characterized by highly performing materials in terms of mechanical resistance and dissipative capacity, and by structures capable of transforming into "resilient" and earthquake-proof spaces (high tables mechanical resistance, "bunker" beds and "lifesaving" cells). Finally, the term "heavy" refers to the installation of systems able to collaborate and improve the anti-seismic capacity of the building, through the realization of partially modular reinforcements and structures - generally in steel - to be placed alongside the surfaces of the room that you want to secure to generate bunker type protection spaces. This first reflection on the possible grouping of the products based on the degrees of intervention, was useful for subsequently framing within a conceptual summary scheme (Fig. 7), three project macro-objectives, concerning the great theme of the protection of people in the event of an earthquake:

1. Development of a hermetic protective space;

2. Development of an open protective system against vertical dynamic and static loads;

3. Development of a system that reduces the probability of collapse of the building structure.

The first two objectives focus on the single piece of furniture, while the third focuses on the development of a system capable of securing a specific space in the building. Each macroobjective includes a series of strategies and intervention actions that characterize the lifesaving performance of a specific product; in particular the following five main strategies have been identified:

1. Increase the mechanical resistance to withstand exceptional loads;

2. Generate variable structural configurations able to withstand exceptional loads;

3. Mitigate and dissipate the stresses generated by an earthquake and/or by any exceptional loads; 


\section{protection of people in the event of an earthquake}

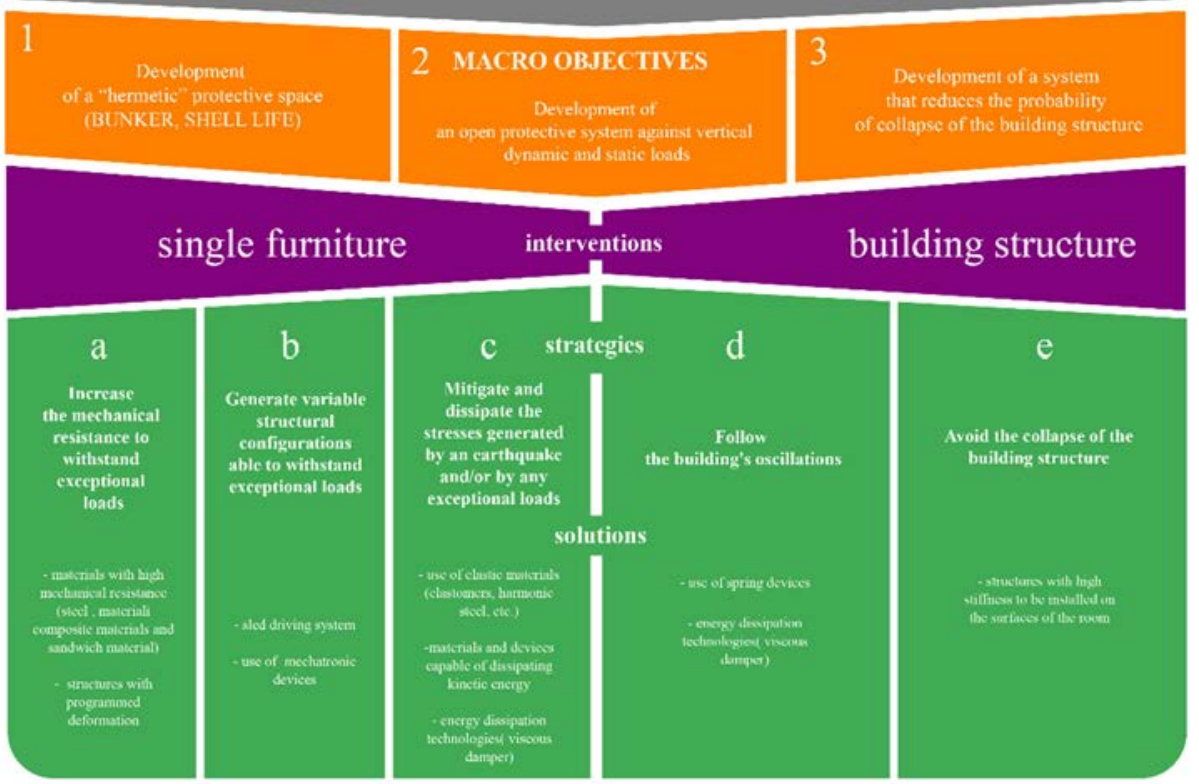

Figure 7: Summary sheet of life-saving strategies adopted.
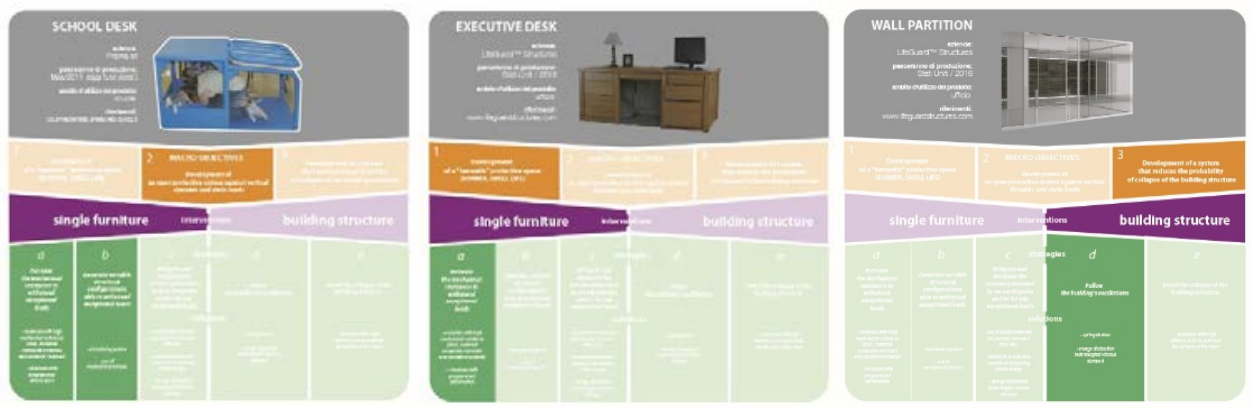

Figure 8: Examples of life-saving strategies for three case studies.

4. Follow the building's oscillations;

5. Avoid the collapse of the building structure.

On the basis of the mapped products, each strategy was able to combine some more detailed design solutions: materials with high mechanical resistance, materials and devices capable of dissipating kinetic energy, structures with high stiffness, structures with programmed deformation, etc. The tree-like scheme thus generated has therefore allowed the construction of a summary sheet of the different life-saving strategies adopted by the 42 mapped products. 
This can represent a valid tool for critical inverse reading of the products, allowing, for each case study, to highlight the main objective, the context of the design intervention, the design strategy that characterizes the anti-seismic performance and the detailed solutions developed and implemented within the products. Below is showed the summary sheet of lifesaving strategies adopted and its declination on three examples of products.

\section{CONCLUSIONS}

The research activity that has been carried out has highlighted the importance and topicality of the subject of safety and passive protection of people in the event of earthquakes and other natural disasters, leading to the identification of 42 life-saving case studies, including commercial products, prototypes, patents and concepts. From the activity of analysis and synthesis of the state of the art of the products, a series of important considerations emerge:

1. In the sector of building and industrial design, the interest for the safety of furniture within the building - non-structural elements - is booming;

2. Since 1995 there has been an exponential increase in patent applications for lifesaving products and devices in the event of an earthquake, with interesting repercussions in the development and marketing of earthquake-proof types of furniture, in particular with regard to beds and work tables;

3. Today it is possible to specify at least three intervention levels for safety:

- The "light" one: foresees the use of anti-tip devices on common wall mounted storage systems;

- The "intermediate" one: involves the development of furniture and protection devices, resilient to dynamic and static loads;

- The "heavy" one: involves intervention on the building envelope for the development of bunkers and life-saving cells;

4. The physical and dimensional characteristics of the cataloged products are substantially incompatible with the spaces and the precariousness of the structures of the urban fabric of the middle Italian historical center;

5. Considering the commercial landscape of life-saving products for schools, there are no design solutions for other types of products such as desks, bookcases and other storage systems;

6. Despite the considerable number of students with disabilities, "inclusive" life-saving types of furniture have not yet been developed;

7. The topic of finding people and monitoring their health status is still little investigated, and is awaiting technological development and platforms capable of coordinating and guiding the rescue forces.

8. To date there are no systems of products - neither as a concept, as a patent nor as a commercial one - that, in a widespread and collaborative manner within an environment, are able to improve the chances of survival in the event of an earthquake.

The general picture of the state of the art of life-saving products and devices in the event of an earthquake, in particular those specialized for the school and office sector, still shows some project areas that have been little investigated and are still awaiting further developments.

In the future, the different types of furniture specialized in people's protection, in addition to fulfilling their traditional peacetime functions, will have to implement a series of lifesaving strategies in wartime which include: 
1. New methods of collaboration between the vertical elements (e.g. wardrobes and equipped walls) and the horizontal ones (counters, desks and desks) of the "system";

2. Integration of smart systems to coordinate the rescue forces and monitor the building state of danger;

3. Inclusive solutions for sensitive subjects such as the elderly, children and the disabled;

4. Use of materials and development of design solutions for the construction of structures that are resilient and light at the same time, to facilitate the installation and application of furniture in buildings in the historic centre;

5. Use of systems for the dissipation of seismic energy, to improve the response to impacts or contribute positively to the anti-seismic capacity of the building.

The design in a systemic perspective of life-saving furniture is probably the most interesting challenge for the designers of tomorrow; it will allow us to overcome the performance offered by a single piece of furniture, while also allowing us to avoid the traditional strategy of structural oversizing, to achieve the ambitious goal of giving greater safety to communities that still live in high-seismic risk contexts and cannot rely on antiseismic building structures for their own protection.

\section{REFERENCES}

[1] Copp, D., American Rescue Team Survival Magazine article. The American Rescue Team International, pp. 32-37, 2000.

[2] Wiss, Janney, Elstner Associates, Earthquake Hazard Mitigation for Nonstructural Elements, pp. 1-48, 2005.

[3] ENEA, MUSEUM, manuale d'impiego, pp. 4-71, Rome, 2001.

[4] Chen, M., Jiang, L., Liu, D.-Z. \& Lyu, J.-H., Primary Research on Emergency SelfRescue Furniture Design for Natural Disasters, 2015.

[5] Masatsuki, T., Midorikawa, S., Ohori, M., Miura, H. \& Kitamura, H., Seismic behavior of office furniture in high-rise buildings due to long-period ground motions. The 14th World Conference on Earthquake Engineering, 12-17 October, 2008.

[6] Portail Humanitaire, Le Concours International sur le Mobilier Parasismique se Poursut. www.portail-humanitaire.org. Accessed on: 1 Feb. 2018.

[7] ANIDIS 2019, XVIII Convegno. http://convegno.anidis.it/index.php/anidis/2019 (Ascoli Piceno). Accessed on: Sep. 2019.

[8] Meguro, K., Ito, D. \& Sato, Y., Efficiency of furniture overturning protection devices during earthquakes: An experimental and numerical study. The 14th World Conference on Earthquake Engineering, Beijing, China, October, 2008.

[9] Petrone, C., Magliulo, G. \& Manfredi, G., Shake Table Tests on Standard and Innovative Temporary Partition Walls, Wiley Online Library, 2017.

[10] LifeGuard ${ }^{\mathrm{TM}}$ Structures, Life-Saving Structures Multi-Hazard Protection in a Familiar Form, pp. 2-8. www.lifeguardstructures.com. Accessed on: 3 Dec. 2018. 